\title{
Development of a Solar Prototype for Roadway
}

\author{
Md Fahim Tanvir Hossain ${ }^{1}$ and Samer Dessouky ${ }^{2, *}$ \\ ${ }^{1}$ Graduate Research \& Teaching Assistant, Department of Civil and Environmental Engineering, University of Texas at San Antonio \\ ${ }^{2}$ Professor, Department of Civil and Environmental Engineering, University of Texas at San Antonio
}

\begin{abstract}
This study is a preview of an ongoing project to develop a solar prototype for roadway to harness solar energy with the addition of transparent shield cover. Solar panel on roadway is a new research arena which has the potential to reform the conventional road network systems. Since pavements are often exposed to a great amount of solar energy throughout the day, they can be used to develop a technique which can accumulate and store this solar energy and later convert it into electricity. The development of the prototype involved selecting several polycarbonate materials as transparent shield covers containing different strength types and light transparency properties. In addition, it involved Finite Element Analysis of the prototypes under static load, Transmittance Spectra test for the transparent covers and generation of power using the prototypes. Initial results show a great potential of implementing this technique as a major pavement energy harvesting technology.
\end{abstract}

\section{Introduction}

Globalization, industrial development, and population growth have led to a surge in the global energy demand in recent years which will result in a major energy crisis in the future. Fossil fuel which comprises oil, coal and natural gas supplies almost 80 percent of total energy [1]. However, fossil fuels are not renewable. As a result, society's overreliance on fossil fuel for energy supply has resulted in a gradual reduction of its source. According to current energy demand, oil and natural gas have approximately 50 years reserves left while coal will run out in 114 years [2]. In addition, usage of fossil fuels causes major climate change. The burning of fossil fuel produces around 21.3 billion tons of $\mathrm{CO}_{2}$ per year [3]. It is estimated that natural process can absorb only half of that. So, there is a continuous net increase of $\mathrm{CO}_{2}$ in the atmosphere. Hence, overreliance on fossil fuel for energy generation also played a major role in global warming.

On this note, renewable energy could play a vital role in reducing the demand for fossil fuels. Among these, solar energy is the most available and a free source of energy. Pavements are often exposed to a great amount of solar energy all over the day. It could be possible to harness this energy using the pavements. Combination of solar energy with the road network could potentially lead to a major role in developing a clean power generation technology. Keeping this mind, several solar road projects have been constructed to develop a standard technique. World's first solar bike path was installed in the Netherlands in 2014. It is known as 'SolaRoad'. Initially, it was $70 \mathrm{~m}$ and later it was extended to $100 \mathrm{~m}$. It produced $9800 \mathrm{kWh}$ per year which exceeded the expected power generation [4]. Later, world's first solar road was introduced in France in 2016. It is $1 \mathrm{~km}$ long and the produced power from this solar road is only used to run that village's street lights. Recently, China has launched world's solar highway in Jinan which has a length of $1 \mathrm{~km}$. It has two lanes with an addition of an emergency lane [5]. In addition, it has a service life of 20 years (Figure 1).

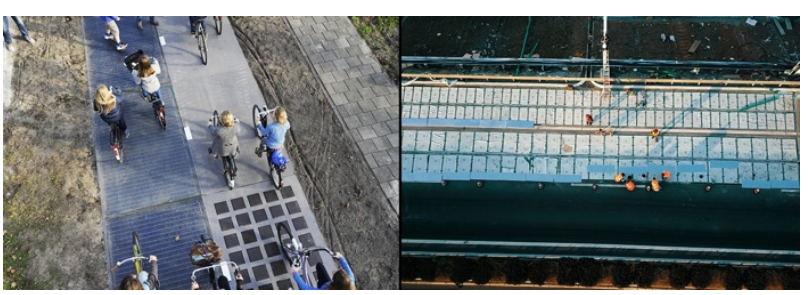

Fig. 1. Solar road projects in Netherlands (left) \& China (right) $[6,7]$.

This paper is dedicated to the construction and design of a solar prototype which can be implemented with the conventional road system. In addition, it included static finite element analysis and comparison of typical pavement against the pavement with a design prototype. This study concludes with a comparison of power generation by different prototype types for the same weather condition.

\section{Objective}

The objective of this paper is to develop a solar prototype on roadway to harness the solar energy from pavement with the addition of a transparent shield cover.

\footnotetext{
* Corresponding author: samer.dessouky@utsa.edu
} 


\section{Developing the solar prototype}

\subsection{Conceptual design}

Traditional practices are often lacking for developing a solar device on roadway. A prototype has been designed to execute this concept (Figure 2). It consists of three layers:

i) Top Layer: On the top layer, there is a transparent polycarbonate which will act as a shield cover. The materials properties were chosen with a view to providing more rigidity than the typical tempered glass. In addition, this layer also serves the purpose of the passing of the sunlight through the polycarbonates to the next layer.

ii) Central Layer: The central layer, the most important part, consists of a flexible, thin film solar panel. In addition, thin film solar cells generally provide better performance under partial shading condition than typical crystalline solar cells due to their unique cell layout [8]. Sunlight passing through the polycarbonates is absorbed by solar cells. Then it is converted into electricity.

iii) Bottom Layer: Beneath the solar panel, there is a wooden frame which supports the entire prototype structure.

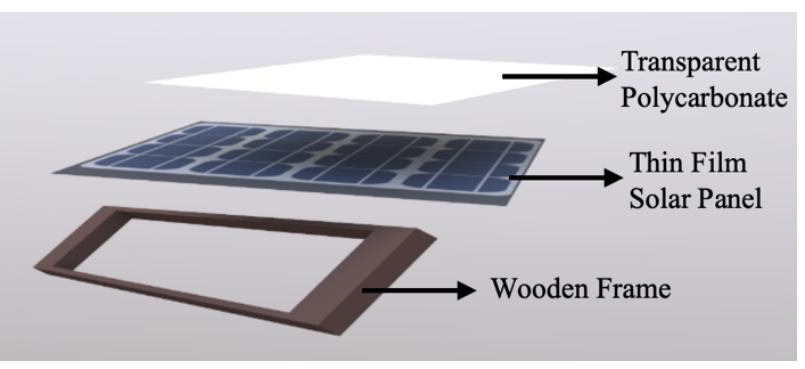

Fig. 2. Schematic design of the prototype.

This solar prototype can be directly applied to the existing road conditions. It is resistant enough to withstand the vehicular loads as well as transparent enough to allow sunlight passing and generate power using the solar cells. Here, the top of the whole prototype surface is acting as a large solar panel.

\subsection{Selection of transparent polycarbonates \& their properties}

The idea is that the polycarbonate will provide the rigidity to protect the fragile solar cells as well as enable the whole structure to withstand the vehicular loads. Two slightly different polycarbonates were picked to compare them in terms of durability and energy production. Since these polycarbonates are not likely to provide significant skid resistance with the road surface, they will be kept in the middle of the lane. As a result, it will get less impact and improved efficiency. In addition, these transparent shield covers contain a wide range of visible light transmittance property which will be elaborated later in this part. All the polycarbonates have higher elastic modulus than typical asphalt pavement. Table 1 shows some comparisons among the properties of the polycarbonates.

Table 1. Comparisons among the properties of the sample polycarbonates.

\begin{tabular}{|c|c|c|}
\hline Properties & Polycarbonate I & Polycarbonate II \\
\hline Thickness & $0.75^{\prime}$ & $0.375^{\prime}$ \\
\hline Material Type & Impact resistant & $\begin{array}{c}\text { Impact resistant } \\
\text { Abrasion resistant }\end{array}$ \\
\hline $\begin{array}{c}\text { Operating } \\
\text { Temp. Range }\end{array}$ & $-40^{\circ} \mathrm{F}$ to $200^{\circ} \mathrm{F}$ & $-40^{\circ} \mathrm{F}$ to $240^{\circ} \mathrm{F}$ \\
\hline $\begin{array}{c}\text { Flexural } \\
\text { Modulus }\end{array}$ & $350 \mathrm{ksi}$ & $336.835 \mathrm{ksi}$ \\
\hline
\end{tabular}

\subsection{Transmittance spectroscopy}

This test was done on the transparent shield covers. The objective of carrying out this test is to do transmittance spectra of the sample polycarbonates showing percent transmittance at each wavelength in the visible light range. The visible spectrum is the electromagnetic spectrum portion which is visible to the human eye. Visible light wavelength range approximately lies between 400 to 700 nanometers [9-11].

\subsubsection{Test setup}

A halogen light containing $6.7 \mathrm{~mW}$ output power and 3 $\mathrm{mm}$ light beam diameter has been used for transmittance spectroscopy test as a source. The passage of the light has been restricted with the addition of an optic fiber. Here, the light passes through a collimating lens in a free beam path. Collimating lenses are placed in parallel position with each other to ensure the transmittance of light in accordance with the same beam path of the source. Later, the transmitted light travels through the optic fiber to the fiber optic spectrometer. Fiber optic spectrometer compares the received light with the source and measures the percent transmittance at each wavelength (Figure 3).

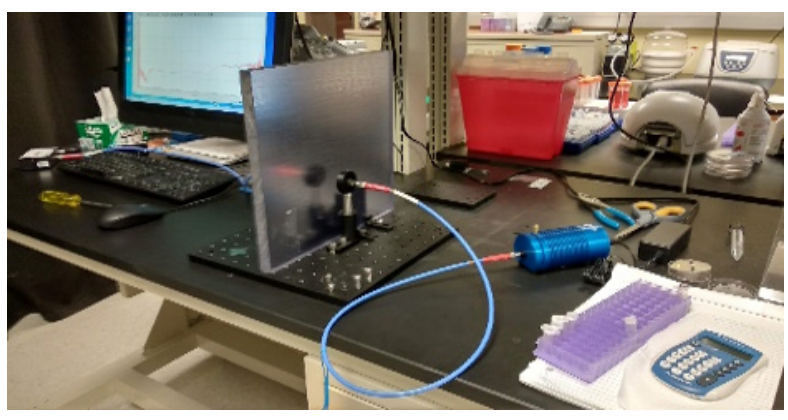

Fig. 3. Test setup of transmittance spectroscopy.

\subsubsection{Observed transparency}

Initially, 100\% light transmittance has been done using the test setup by keeping the free light beam path between the two collimating lenses. No object was put between the lenses at that time. Later, transparent shield covers have been placed there to compare the 
transmittance spectra between them. Wavelengths of 450 $\mathrm{nm}$ to $750 \mathrm{~nm}$ have been used for visible light range. Approximately $30 \%$ and $90 \%$ transparency were observed respectively for prototype I and II from the transmittance spectroscopy test (Figure 4).

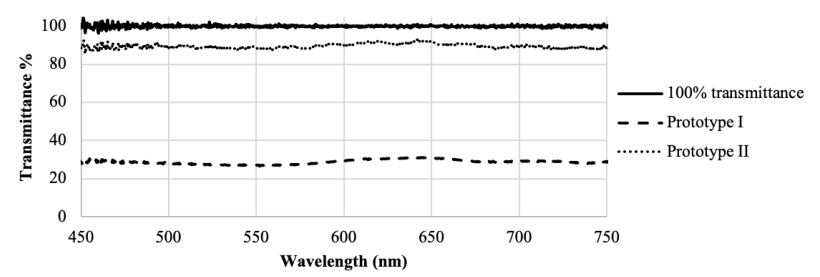

Fig. 4. Percent transmittance comparison among the sample polycarbonates.

\subsection{Finite element}

Finite element analysis was applied to model the pavement-tire load system with a view to design the optimum configuration of the prototype and analyze the performance of a pavement using the design prototype with a typical one.

Three-dimensional finite element analysis on a flexible pavement structure was performed using the ABAQUS commercial modeling program. In this section, the static structural analysis was done on the pavement model. The pavement dimension was selected based on a typical solar panel size. A typical pavement layout was designed to analyze the behavior of an extended structure.

The analyzed pavement structure had a length of $1193.8 \mathrm{~mm}$ and a width of $533.4 \mathrm{~mm}$ like a typical solar panel. The same dimension was also used for the solar prototype.

\subsubsection{Assumptions for loading \& boundary condition}

A typical truck tire was assumed for analyzing the pavement-tire load system. 6" tire imprint length was presumed to be acted on the center of the tire and the minimum safe distance between front and rear tires were considered 4".

Boundary conditions were selected to analyze the actual behavior of an asphalt pavement structure. No displacement was considered in lateral, axial and longitudinal direction. Non-slip tie constraints were used between the different layers of the pavement structure (e.g., between asphalt and base layer).

\subsubsection{Finite Element Analysis}

The finite element mesh was finer near the prototype and coarser away from it. It provides higher resolution around the prototype and the top layer. Observed displacement from the pavement with the addition of transparent shield cover and wooden frame (2.645 microns) showed a slightly lower value (Figure 5) than the typical one (7.115 microns). Hence, initial findings from the finite element analysis show promising result to implement the solar prototype on top of the typical pavement.

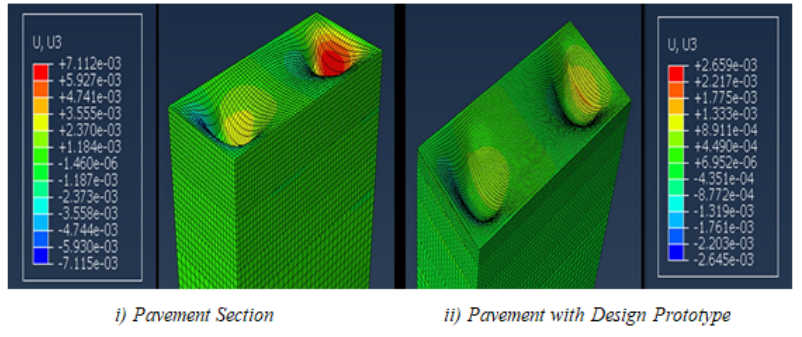

Fig. 5. FE Analysis of pavement i) with and ii) without design prototype.

\section{Design experiment in outdoor condition}

This part covers the comparison of power generation using the prototypes in outdoor condition. 3 thin film solar panels with similar (3.08 Watt and 15.4 Volt) electricity generation properties were used to determine the efficiency of the prototypes. These three panels represented 3 criteria:

1. Solar Panel without any transparent shield cover (control)

2. Solar Panel with Prototype I

3. Solar Panel with Prototype II

A wide range of resistor values was used to find an optimum power level. During the data collection period, the weather was cloudy but there was no rain. Comparison of power generation against resistor among these 3 criteria are given below in Fig 6 .

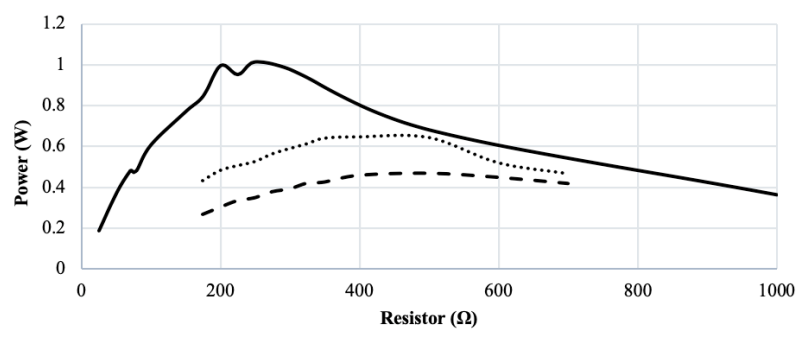

Fig. 6. Power generation comparison in outdoor.

Figure 6 shows that Prototype II produced approximately $50-65 \%$ produced power of the control solar panel. Due to lower transparency, Prototype I generated almost $30 \%$ power of the control solar panel. Power generation from Prototype I lied between $60 \%$ to $70 \%$ of the produced power from Prototype II. Here, Prototype II generated $0.65 \mathrm{~W}$ at their peak, while Prototype I produced $0.46 \mathrm{~W}$. It can be seen that Prototype I and II approximately produce respectively 4 $\mathrm{kWh}$, and $5.7 \mathrm{kWh}$ per year.

\section{Cost analysis}

Each prototype required a transparent shield cover, a thin film solar panel and a wooden frame for the construction process. The cost summary and per energy cost of each prototype are given below in Table 2 .

Table 2. Cost per energy for the prototypes. 


\begin{tabular}{|c|c|c|c|c|c|}
\hline Prototype & $\begin{array}{c}\text { Shield } \\
\text { Cover } \\
\text { Cost } \\
\mathbf{( \$ )}\end{array}$ & $\begin{array}{c}\text { Solar } \\
\text { Panel } \\
\text { Cost } \\
\mathbf{( \$ )}\end{array}$ & $\begin{array}{c}\text { Frame } \\
\text { Cost } \\
\mathbf{( \$ )}\end{array}$ & $\begin{array}{c}\text { Total } \\
\text { Cost } \\
\mathbf{( \$ )}\end{array}$ & $\begin{array}{c}\text { Cost Per } \\
\text { Energy } \\
\mathbf{( \$ / k W h )}\end{array}$ \\
\hline $\begin{array}{c}\text { Prototype } \\
\text { I }\end{array}$ & 232 & 71 & 4 & 307 & 76.75 \\
\hline $\begin{array}{c}\text { Prototype } \\
\text { II }\end{array}$ & 38 & 71 & 4 & 113 & 19.8 \\
\hline
\end{tabular}

It takes $\$ 19.8$ per kWh generation using Prototype II. On the other hand, it is estimated to range between $\$ 0.15$ and $\$ 0.3$ per kWh from fossil-fueled power plants [12].

\section{Conclusions}

This paper provides a preview of an ongoing project to develop a solar prototype with the addition of a transparent shield cover. It also includes the cost per energy analysis for the prototypes. The prototypes are capable of producing an average of almost $600 \mathrm{~mW}$ continuously over a period of 8 hours a day. Although the produced power may look very small and costineffective in comparison with traditional electronic devices, the generated power can be used to run the street lights, to power LED lights for signage and safety concerns and to light up when a pedestrian is crossing in order to alert the drivers. Instead of sending all the cables to the rural areas, this power can be supplied to these areas to save a lot of time and money. The main advantage of implementing this solar prototype is that it can be directly applied to the existing road conditions and the generated energy using the prototype is clean as well as sustainable. Initial results show a great potential of implementing this technique as a major pavement energy harvesting technology. This is still a work in progress. More work will be done on trying this on the roadway and the parking lot under moving traffic. Further study will be expanded on the longevity and durability of the polycarbonates to produce the power and sustain the traffic.

\section{References}

1. IEA. Key World Energy Statistics. International Energy Agency, 2014.

2. Retrieved October 7, 2018 from https://ourworldindata.org/how-long-before-we-runout-of-fossil-fuels

3. Dukiya, J. J. "Energy Shortage, Climate Change and the Challenge of Intelligent Transport System (ITS) Adaption in African Countries."

4. Retrieved March 11, 2018 from https://cleantechnica.com/2017/03/12/dutch-solarbike-path-solaroad-successful-expanding/

5. Retrieved April 24, 2018 from https://cleantechnica.com/2017/12/30/china-opens1-kilometer-long-solar-road/

6. Retrieved November 9, 2018 from https://www.sciencealert.com/solar-roads-in-thenetherlands-are-working-even-better-than-expected

7. Retrieved July 4, 2018 from https://www.today.ng/multimedia/photo/chinabuilds-worlds-solar-powered-highway-42438

8. Tzikas, C., Gómez, G., Donker, M., Bakker, K., Smets, A.H.M., and Folkerts, W. (2017). Do thin film PV modules offer an advantage under partial shading conditions?. Solar Energy.

9. Retrieved October 2, 2018 from https://en.wikipedia.org/wiki/Visible_spectrum

10. Retrieved October 27, 2018 from https://en.wikipedia.org/wiki/Light

11. Retrieved October 2, 2018 from https://www.xrite.com/servicesupport/visible_spectrum

12. Papagiannakis, A.T., Dessouky, S., Montoya, A., and Roshani, H. (2016). Energy harvesting from roadways. Procedia Computer Science 83: 758-765. 